\title{
Bazı Yapay Mera Karışımlarında Ekim Yöntemleri ve Azot Dozlarının Fide Gelişmesine Etkileri*
}

\author{
Altıngül ÖZASLAN PARLAK ${ }^{1}$ \\ Hayrettin EKIZ
}

Geliş Tarihi: 10.05.2006

\begin{abstract}
Öz: Bu araştırma Orta Anadolu kıraç koşullarında bazı yapay mera karışımlarında ekim yöntemleri ve azot dozlarının yem verimi ve kalitesine etkilerinin belirlenmesi amacıyla 2001 yılında Ankara Üniversitesi Ziraat Fakültesi Tarla Bitkileri Bölümü deneme tarlasında yürütülmüştür. Araştırmada otlak ayrığı, kılçıksız brom, korunga ve çayır düğmesi bitkilerinden ikili ve üçlü karışımlar oluşturulmuştur. Serpme, aynı sıraya ve farklı sıralara ekim yapılarak azotun 0,5 ve $10 \mathrm{~kg} / \mathrm{da}$ dozları uygulanmıştır. Karışımda bulunan bitkilerin fide kuru ağırığı ekim yöntemleri ve azot dozlarından etkilenmemiştir. Ekim yöntemleri metrekaredeki fide sayısı ve fide çıkış oranları üzerinde etkili olmuştur. Farklı sıraya yapılan ekimlerde otlak ayrığı ve kılçıksız bromun hem metrekaredeki fide saysı hem de fide çıkış oranı yüksek bulunmuştur. Meyvesiyle ekilen korunga ve çayır düğmesinde en fazla fide çıkış oranı aynı sıraya yapılan ekimlerde elde edilmiştir.
\end{abstract}

Anahtar Kelimeler: otlak ayrığı, kılçıksız brom, korunga, çayır düğmesi, karışımlar, ekim yöntemleri, azot dozları, fide çıkışı

\section{The Effect of Sowing Methods and Nitrogen Doses on the Seedling Growth in Artificial Range Mixtures}

\begin{abstract}
This study was conducted on the University of Ankara, Faculty of Agriculture, experimental field of Field Crops Department in order to determine the effects of sowing methods and nitrogen doses in to the yield and quality of various artificial range mixtures in Central Anatolia in 2001. Crested wheatgrass, smooth bromegrass, sainfoin and burnet were used as research materials for binary and trible mixtures of grasses with sainfoin or burnet. Seeding patterns were broadcast, mixed rows and alternate rows and 0,5 and $10 \mathrm{~kg} / \mathrm{da} \mathrm{N}$ were applied to each mixture. Dry weights of the seedlings in mixture were not affected from sowing methods and nitrogen doses. Sowing methods affected both the number of seedling and emergency rates per square meter. Emergency rates and number of seedling of crested wheatgrass and smooth brome grass in different lines were higher per square meter. Emergency rate of sainfoin and burnet pods was found the highest within the same row.
\end{abstract}

Key Words: crested wheatgrass, smooth bromegrass, sainfoin, burnet, mixtures, sowing methods, nitrogen doses, seedling emergence

\section{Giriş}

Hayvancılığın en önemli sorunu olan kaba yem açığı, yem bitkileri üretiminin artırılması, mevcut mera alanlarının ıslah edilmesi ve tarla tarımı içerisinde yem bitkileri ekim alanlarının genişletilmesiyle mümkündür. 1998 yılında 4342 sayılı Mera Kanunu'nun çıkarılmasıyla bazı bölgelerimizde mera tespit ve tahdit işlemleri bitirilmiş ve ıslah çalışmalarına başlanmıştır. Merada ıslah çalışmalarında değişik şekillerde tohumlama yapılmaktadır. Yapay meraların oluşturulmasında başarı sağlanabilmesi için fide dönemi oldukça önemlidir. Çok küçük olan yem bitkileri tohumlarının çıkışında ekim derinliğini iyi ayarlamak gerekir. Ekim derinliğini etkileyen en önemli faktörlerden biri de ekim şeklidir. Ekim derinliğinin artmasıyla toprak nemi, buna bağlı olarak da çimlenme artmakta, fakat çıkış azalmaktadır (Vallentine, 1980). Yapılan çalışmalarda yeterli nem olmak kaydıyla buğdaygil yem bitkilerinin ekim derinliğinin az olması durumunda çıkışın fazla olduğu ve başarılı bir tesis kurulduğu belirlenmiştir (Mutz ve Scifres 1975, Sepaskhah ve Ardekani 1978 Lafond ve Fowler 1989, Young 1992).

\footnotetext{
* Doktora Tezinden hazırlanmıştır.

${ }_{1}^{1}$ Çanakkale Onsekiz Mart Üniv. Ziraat Fak. Tarla Bitkileri Bölümü-Çanakkale

2 Ánkara Üniv. Ziraat Fak. Tarla Bitkileri Bölümü-Ankara
} 
Kurt (1978) Orta Anadolu kıraç koşullarında yapay mera kurmak için mavi ayrık, kılçıksız brom ve yoncayı karıştırarak ekmiştir. Karışıma giren bu bitkilerinekiminde değişik tohum oranlarını kapsayan 15 karışım oluşturmuştur. Araştırma sonuçlarına göre, mavi ayrık, kılçıksız brom ve yoncanın $\mathrm{m}^{2}$ 'deki ortalama fide sayıları sırasıyla 49.73, 58.91, 23.42 adet olarak belirlenmiştir.

Bakır ve ark. (1992) salyangoz yoncası ile otlak ayrığından oluşan karışımlar kullanarak yapay mera kurma olanaklarını araştırmak amacı ile Ankara'da 4 yı süreyle yaptıkları çalışmada, aynı ve farklı sıralara ekilen değişik oranlardaki karışımlardan $\mathrm{m}^{2}$ 'de 17.0 41.8 arasında otlak ayrığı ve 3.6-38.7 arasında değişen sayılarda salyangoz yoncası fidesi elde edilmiştir.

Karakurt (2000) Ankara şartlarında otlak ayrığı, kılçıksız brom ve mavi ayrık bitkileri kullanılarak yapılan denemede en yüksek fide sayısı 376.7 adet $/ \mathrm{m}^{2}$ ile mavi ayrık bitkisinden elde edilmiştir. Bunu sırasıyla otlak ayrığı (357.5 adet $/ \mathrm{m}^{2}$ ) ve kılçıksız brom (301.9 adet $/ \mathrm{m}^{2}$ ) takip etmiştir. Fide kuru ağırığı kılçıksız brom ve mavi ayrıkta $1.7 \mathrm{~g}$ olurken, otlak ayrığında $0.8 \mathrm{~g}$ olarak bulunmuştur.

Ünal (2000) Orta Anadolu kıraç şartlarında nohut geveni, otlak ayrığı ve mavi ayrık ile yapay mera kurma imkanlarını belirlemek için yürüttüğü çalışmada, ortalama fide sayısı nohut geveni, otlak ayrığı ve mavi ayrıkta sırasıyla $22.89,63.75$ ve 61.35 adet $/ \mathrm{m}^{2}$ olarak bulunmuştur. Ortalama fide yaş ağırlığı ve kuru ağırlığ ise sırasıyla nohut geveninde 1.30 ve $0.326 \mathrm{~g}$, otlak ayrığında $2.06 \mathrm{~g}$ ve $0.616 \mathrm{~g}$, mavi ayrıkta ise $4.09 \mathrm{~g}$ ve $1.325 \mathrm{~g}$ olarak belirlenmiştir.

Ankara şartlarında yonca, korunga, kılçıksız brom ve otlak ayrığıyla yapılan karışım denemesinde Albayrak (2003) $\mathrm{m}^{2}$ 'deki fide sayıları ortalama sırasıyla $56.42,50.17,45.42$ ve 60.17 adet olarak belirlemiştir. Fide yaş ağırlıkları yine sırasıyla ortalama 0.834 , $4.101,1.328$ ve $1.255 \mathrm{~g}$ olarak ölçülmüştür.

$\mathrm{Bu}$ araştırmada Orta Anadolu şartlarında yapay mera tesisi için bazı mera karışımlarında farklı ekim şekilleri ve azot dozlarının fide gelişimine etkileri belirlenmeye çalışılmıştır.

\section{Materyal ve Yöntem}

$\mathrm{Bu}$ araştırma 2001-2003 yılları arasında Ankara Üniversitesi Ziraat Fakültesi Tarla Bitkileri Bölümü deneme tarlasında kuru şartlarda yürütülmüştür. Araştırma sahasının toprakları tuzsuz, hafif alkali, 0-30 $\mathrm{cm}$ derinlikte kireçli, 30-60 cm derinlikte orta kireçli, fosfor bakımından az, potasyum bakımından yüksek, organik madde bakımından az olarak sınıflandırılmaktadır. Denemenin kurulduğu yıldaki toplam yağış miktarı $(437.4 \mathrm{~mm})$ uzun yılların yıllık yağış toplamından (383.1 mm) yüksek olmuştur. Mayıs ayında $110.0 \mathrm{~mm}$ yağış düşerek uzun yıllar ortalamasının iki katı şeklinde gerçekleşmiştir. Yıllık ortalama sıcaklık uzun yıllar ortalamasında $11.7{ }^{\circ} \mathrm{C}$ iken, fide döneminde $13.5{ }^{\circ} \mathrm{C}$ olarak gerçekleşmiştir. Uzun yıllar ortalamasına göre yıllık ortalama nispi nem \%60.5 iken, 2001 yılında \%58.4 olarak kaydedilmiştir.

Araştırmada materyal olarak Ankara Üniversitesi Ziraat Fakültesi Tarla Bitkileri Bölümünden temin edilen otlak ayrığı (Agropyron cristatum (L.) Gaertn.)'nın Fairway varyetesi, kılçıksız brom (Bromus inermis Leys.)'un Ungarische-Trespe varyetesi, korunga (Onobrychis sativa (Lam.))'nın Gözlü ekotipi ile çayır düğmesi (Sanguisorba minor Scop.)'nin Bünyan-80 çeşidi kullanılmıştır.

Araştırma tesadüf bloklarında bölünen bölünmüş deneme deseninde faktöriyel düzenlemeye göre üç tekerrürlü olarak planlanmıştır. Ana parsellere karışımlar, alt parsellere ekim şekilleri, altın altı parsellere de gübre dozları yerleştirilmiştir. Her parsel $10.5 \mathrm{~m}^{2}$ lik alana sahip olmuş ve deneme 108 parselden meydana gelmiştir. Dekara korungadan 10 $\mathrm{kg}$, buğdaygil yem bitkilerinden $2 \mathrm{~kg}$ ve çayır dügmesinden $3 \mathrm{~kg}$ tohum 19 Mart 2001 tarihinde ekilmiştir. Yabancı ot mücadelesi elle yapılmıştır. Karışımlar metin içerisinde $\mathrm{K}$ harfi ile gösterilip, $\mathrm{K} 1=$ Korunga + otlak ayrığı, K2= korunga + otlak ayrığı + kılçıksız brom, K3= çayır düğmesi + otlak ayrığı, K4= çayır düğmesi + otlak ayrığı + kılçıksız brom şeklinde belirlenmiştir. Karışımlarda buğdaygiller \%66 oranında yer almıştır. Ekim yöntemi $E$ harfi ile gösterilmiştir. E1= serpme ekim, E2= aynı sıraya ekim ve E3= farklı sıralara ekim şeklinde ifade edilmiştir. Serpme ekimde tohumlar karıştırılarak parsellere elle serpilmiştir. Aynı sıraya ekimde $35 \mathrm{~cm}$ aralıklarla markörle açılan sıralara her iki veya üç türün tohumları karıştırılarak ekilmiştir. Farklı sıralara ekimde karışımda bulunan her iki veya üç türün tohumları $35 \mathrm{~cm}$ aralıklı sıralara ayrı ayrı ekilmiştir. Azotlu gübre olarak amonyumsülfat (\% 21-23 N) ilkbaharda atılmıştır. Gübre dozları N harfi ile tanımlanıp $\mathrm{N} 0=0 \mathrm{~kg} \mathrm{~N} / \mathrm{da}, \mathrm{N} 5=5 \mathrm{~kg} \mathrm{~N} / \mathrm{da}$ ve $\mathrm{N} 10=10$ $\mathrm{kg} \mathrm{N} /$ da olarak gösterilmiştir.

Araştırmada elde edilen veriler tesadüf bloklarında bölünen bölünmüş parseller deneme desenine göre bilgisayarda MSTATC programında varyans analizine tabi tutulmuş ve değerlendirilmiştir. Bulunan ortalamalar arasındaki farkın önemlilik kontrolü Duncan testi ile belirlenmiştir (Düzgüneş vd. 1987). 


\section{Bulgular ve Tartışma}

Fide kuru ağırlığı: Fide kuru ağırığı yönünden otlak ayrığı, kılçıksız brom, korunga ve çayır düğmesinden oluşan karışımlar arasındaki farklar istatistiki olarak önemsiz olmuştur (Çizelge 1, 2, 3 ve 4).

Çizelge 1. Otlak ayrığının ortalama fide kuru ağırlıkları (g).

\begin{tabular}{|c|c|c|c|c|c|}
\hline \multirow[t]{2}{*}{ Karışım } & \multirow{2}{*}{$\begin{array}{l}\text { Ekim } \\
\text { şekli }\end{array}$} & \multicolumn{3}{|c|}{ Gübre dozları } & \multirow{2}{*}{ Ortalama } \\
\hline & & NO & N5 & N10 & \\
\hline \multirow{3}{*}{ K1 } & $\mathrm{E} 1$ & 1.97 & 2.20 & 1.47 & 1.88 \\
\hline & E2 & 1.80 & 2.15 & 1.66 & 1.87 \\
\hline & E3 & 2.45 & 2.26 & 2.34 & 2.34 \\
\hline \multirow[t]{2}{*}{ Ortalama } & & 2.07 & 2.20 & 1.82 & 2.03 \\
\hline & E1 & 1.71 & 1.62 & 1.98 & 1.77 \\
\hline \multirow[t]{2}{*}{ K2 } & E2 & 1.96 & 1.91 & 2.07 & 1.98 \\
\hline & E3 & 2.17 & 2.26 & 2.21 & 2.21 \\
\hline \multirow[t]{2}{*}{ Ortalama } & & 1.95 & 1.93 & 2.09 & 1.99 \\
\hline & $\mathrm{E} 1$ & 1.95 & 2.28 & 2.16 & 2.13 \\
\hline \multirow[t]{2}{*}{ K3 } & E2 & 2.03 & 1.78 & 2.46 & 2.09 \\
\hline & E3 & 1.69 & 2.45 & 2.00 & 2.05 \\
\hline \multirow[t]{2}{*}{ Ortalama } & & 1.89 & 2.17 & 2.21 & 2.09 \\
\hline & E1 & 1.71 & 1.82 & 1.98 & 1.84 \\
\hline \multirow[t]{2}{*}{ K4 } & E2 & 1.59 & 1.80 & 1.68 & 1.69 \\
\hline & E3 & 1.84 & 2.05 & 1.74 & 1.88 \\
\hline \multicolumn{2}{|l|}{ Ortalama } & 1.71 & 1.89 & 1.80 & 1.80 \\
\hline \multirow{3}{*}{$\begin{array}{c}\text { Karışım } \\
\text { lar } \\
\text { Ort. }\end{array}$} & E1 & 1.83 & 1.98 & 1.90 & 1.91 \\
\hline & E2 & 1.84 & 1.91 & 1.97 & 1.91 \\
\hline & E3 & 2.04 & 2.25 & 2.07 & 2.12 \\
\hline \multicolumn{2}{|c|}{ Genel ortalama } & 1.91 & 2.05 & 1.98 & 1.98 \\
\hline
\end{tabular}

Çizelge 2. Kılçıksız bromun ortalama fide kuru ağırıkları (g).

\begin{tabular}{cccccc}
\hline \multirow{2}{*}{ Karışım } & Ekim & \multicolumn{3}{c}{ Gübre dozları } & \multirow{2}{*}{ Ortalama } \\
\cline { 3 - 5 } & şekli & N0 & N5 & N10 & \\
\hline \multirow{2}{*}{ K2 } & E1 & 3.96 & 1.76 & 1.95 & 2.56 \\
& E2 & 2.35 & 2.42 & 2.32 & 2.36 \\
& E3 & 2.12 & 2.56 & 2.75 & 2.48 \\
\hline Ortalama & & 2.81 & 2.25 & 2.34 & 2.47 \\
\hline \multirow{2}{*}{ K4 } & E1 & 2.07 & 2.00 & 2.02 & 2.03 \\
& E2 & 1.95 & 2.18 & 2.43 & 2.19 \\
& E3 & 1.93 & 1.86 & 2.26 & 2.02 \\
\hline Ortalama & & 1.99 & 2.01 & 2.24 & 2.08 \\
\hline Karışım & E1 & 3.02 & 1.88 & 1.99 & 2.29 \\
lar & E2 & 2.15 & 2.30 & 2.38 & 2.28 \\
Ort. & E3 & 2.03 & 2.21 & 2.51 & 2.25 \\
\hline Genel ortalama & 2.40 & 2.13 & 2.29 & 2.27 \\
\hline \multicolumn{2}{l}{ Önemlilik: Bütün faktörler ve etkileşimler önemsiz. }
\end{tabular}

Çizelge 3. Korunganın ortalama fide kuru ağırlıkları (g).

\begin{tabular}{|c|c|c|c|c|c|}
\hline \multirow[t]{2}{*}{ Karışım } & \multirow{2}{*}{$\begin{array}{l}\text { Ekim } \\
\text { şekli }\end{array}$} & \multicolumn{3}{|c|}{ Gübre dozları } & \multirow{2}{*}{ Ortalama } \\
\hline & & NO & N5 & N10 & \\
\hline \multirow{3}{*}{ K1 } & E1 & 9.52 & 11.93 & 10.97 & 10.81 \\
\hline & E2 & 11.07 & 13.49 & 11.15 & 11.90 \\
\hline & E3 & 10.68 & 12.28 & 12.31 & 11.76 \\
\hline Ortalama & & 10.42 & 12.57 & 11.48 & 11.49 \\
\hline \multirow{3}{*}{ K2 } & E1 & 10.72 & 10.53 & 9.36 & 10.21 \\
\hline & E2 & 10.06 & 9.40 & 7.61 & 9.02 \\
\hline & E3 & 8.21 & 8.66 & 10.32 & 9.06 \\
\hline Ortalama & & 9.66 & 9.53 & 9.10 & 9.43 \\
\hline Karışım & E1 & 10.12 & 11.23 & 10.17 & 10.51 \\
\hline lar & E2 & 10.56 & 11.45 & 9.38 & 10.46 \\
\hline Ort. & E3 & 9.45 & 10.47 & 11.32 & 10.41 \\
\hline Genel orta & lama & 10.04 & 11.05 & 10.29 & 10.46 \\
\hline
\end{tabular}

Çizelge 4. Çayır düğmesinin ortalama fide kuru ağırlıkları (g).

\begin{tabular}{cccccc}
\hline \multirow{2}{*}{ Karışım } & Ekim & \multicolumn{3}{c}{ Gübre dozları } & \multirow{2}{*}{ Ortalama } \\
\cline { 3 - 5 } & şekli & N0 & N5 & N10 & \\
\hline \multirow{2}{*}{ K3 } & E1 & 4.23 & 4.17 & 3.82 & 4.07 \\
& E2 & 4.27 & 5.28 & 4.17 & 4.57 \\
& E3 & 3.48 & 4.11 & 4.23 & 3.94 \\
\hline Ortalama & & 3.99 & 4.52 & 4.07 & 4.20 \\
\hline \multirow{2}{*}{ K4 } & E1 & 3.79 & 4.03 & 3.17 & 3.66 \\
& E2 & 4.28 & 5.26 & 4.72 & 4.75 \\
\hline Ortalama & E3 & 3.69 & 3.58 & 4.41 & 3.89 \\
\hline Karışım & E1 & 3.92 & 4.29 & 4.10 & 4.10 \\
lar & E2 & 4.01 & 4.10 & 3.50 & 3.87 \\
Ort. & E3 & 3.59 & 5.27 & 4.44 & 4.66 \\
\hline \multicolumn{2}{l}{ Genel ortalama } & 3.96 & 4.85 & 4.32 & 3.92 \\
\hline \multicolumn{2}{l}{ Önemlilik: Bütün faktörler ve etkileşimler önemsiz. }
\end{tabular}

Önemlilik: Bütün faktörler ve etkileşimler önemsiz.

Karışımlar ve azot seviyelerinin ortalamasına göre otlak ayrığı, kılçıksız brom, korunga ve çayır düğmesinin fide kuru ağırlıkları ortalama olarak sırasıly $1.98,2,27, \quad 10.46$ ve $4.15 \mathrm{~g}$ olarak belirlenmiştir.

Değişik karışımların ve azot dozlarının ekilen türlerin fidelerinin kuru ağırlıklarına etkilerinin önemsiz olması, ekimden sonraki ilk dokuz haftada fideler arasında belirgin bir yarışmanın olmadığını ve verilen azotun fide dönemindeki gelişmeyi pek etkilemediğini göstermektedir. Zira uygun tohumluk miktarı ile ekim yapıldığında, yavaş gelişen fideler fazla toprak altı ve toprak üstü aksam oluşturmadıklarından birbirleri ile yarışmaya gerek duymamaktadırlar. Aynı şekilde zayıf kök gelişimi verilen azotun başlangıçta yeterince alınmamasına sebep olmaktadır. Bu yüzden bu araştırmada elde edilen bulgular Karakurt (2000), Ünal (2000) ve Albayrak (2003) tarafından elde edilen bulgularla benzerlik göstermiştir. 
Metrekaredeki fide sayısı: Otlak ayrığının $\mathrm{m}^{2}{ }^{2}$ deki fide sayısı üzerine sadece ekim şekli ve karışım x ekim şekli etkileşimi önemli bulunmuştur. En yüksek fide sayıs 14.91 adet $/ \mathrm{m}^{2}$ ile farklı sıralara ekimden elde edilirken, aynı sıraya ekimde 11.14 adet $/ \mathrm{m}^{2}$, serpme ekimde ise 9.79 adet $/ \mathrm{m}^{2}$ fide sayılmıştır (Çizelge 5). Karışımlarda otlak ayrığının fide sayısı ekim şekillerine göre önemli ölçüde değişmiştir. En yüksek fide sayılarına farklı sıraya ekilen korunga + otlak ayrığı + kılçıksız brom karışımı $\left(17.65 \mathrm{fide} / \mathrm{m}^{2}\right)$ ile korunga + otlak ayrığı karışımı (16.85 fide $/ \mathrm{m}^{2}$ ) sahip olmuştur. En az fide (7.69 adet) aynı sıraya ekilen korunga + otlak ayrığı + kılçıksız brom parsellerinde sayılmıştır.

Kılçıksız bromun fide sayılarında ekim şekli ve karışım x ekim şekli etkileşimi önemli, diğer faktör ve etkileşimler önemsiz bulunmuştur. En fazla fide (32.24 adet $/ \mathrm{m}^{2}$ ) farklı sıralara ekimde sayılırken, en az fide $\left(17.73 \mathrm{adet} / \mathrm{m}^{2}\right.$ ) serpme ekimden elde edilmiştir (Çizelge 6). Karışımlar ile ekim şekli birlikte değerlendirildiğinde, $36.99 \mathrm{adet} / \mathrm{m}^{2}$ ile en çok fideye farklı sıraya ekilen korunga + otlak ayrığı + kılçıksız brom karışımında rastlanmıştır. Bunu 27.49 adet ile aynı şekilde ekilen çayır düğmesi + otlak ayrığı + kılçıksız brom karışımı takip etmiştir.

Çizelge 5. Otlak ayrığının ortalama $\mathrm{m}^{2}$, deki fide sayısı $\left(\operatorname{adet} / \mathrm{m}^{2}\right)$.

\begin{tabular}{|c|c|c|c|c|c|c|}
\hline \multirow[t]{2}{*}{ Karışım } & \multirow{2}{*}{$\begin{array}{l}\text { Ekim } \\
\text { şekli }\end{array}$} & \multicolumn{3}{|c|}{ Gübre dozları } & \multirow{2}{*}{\multicolumn{2}{|c|}{ Ortalama }} \\
\hline & & No & N5 & N10 & & \\
\hline \multirow{3}{*}{ K1 } & $\overline{\mathrm{E} 1}$ & 8.42 & 14.99 & 11.44 & 10.61 & $\mathrm{C}-\mathrm{F}$ \\
\hline & E2 & 15.45 & 11.70 & 11.44 & 12.86 & $\mathrm{BC}$ \\
\hline & & 17.03 & 15.71 & 17.81 & 16.85 & $A B$ \\
\hline Ortalama & & 13.63 & 14.14 & 12.55 & 13.44 & \\
\hline \multirow{3}{*}{ K2 } & E1 & 8.43 & 7.38 & 7.64 & 7.82 & EF \\
\hline & E2 & 8.30 & 9.35 & 5.40 & 7.69 & $\mathrm{~F}$ \\
\hline & E3 & 16.34 & 18.05 & 18.58 & 17.65 & A \\
\hline Ortalama & & 11.02 & 11.59 & 10.54 & 11.05 & \\
\hline \multirow{3}{*}{ K3 } & E1 & 11.57 & 14.73 & 10.32 & 12.21 & CD \\
\hline & E2 & 13.54 & 12.36 & 16.30 & 14.07 & $A-C$ \\
\hline & E3 & 12.69 & 11.71 & 11.64 & 12.01 & $C-E$ \\
\hline Ortalama & & 12.60 & 12.93 & 12.75 & 12.76 & \\
\hline \multirow{3}{*}{ K4 } & E1 & 9.36 & 7.77 & 8.43 & 8.52 & $\mathrm{D}-\mathrm{F}$ \\
\hline & E2 & 8.43 & 13.04 & 8.30 & 9.93 & $\mathrm{C}-\mathrm{F}$ \\
\hline & E3 & 13.57 & 14.49 & 11.33 & 13.13 & $\mathrm{BC}$ \\
\hline Ortalama & & 10.45 & 11.77 & 9.35 & 10.53 & \\
\hline \multirow{3}{*}{$\begin{array}{c}\text { Karışım } \\
\text { lar } \\
\text { Ort. }\end{array}$} & E1 & 9.44 & 11.22 & 8.70 & 9.79 & B \\
\hline & E2 & 11.43 & 11.62 & 10.36 & 11.14 & B \\
\hline & E3 & 14.91 & 14.99 & 14.84 & 14.91 & A \\
\hline \multicolumn{2}{|c|}{ Genel ortalama } & 11.93 & 12.61 & 11.30 & 11.95 & \\
\hline
\end{tabular}

Çizelge 6. Kılçıksız bromun ortalama $\mathrm{m}^{2}$ deki fide sayısı $\left(\right.$ adet $\left./ \mathrm{m}^{2}\right)$.

\begin{tabular}{|c|c|c|c|c|c|c|}
\hline \multirow[t]{2}{*}{ Karışım } & \multirow{2}{*}{$\begin{array}{l}\text { Ekim } \\
\text { şekli }\end{array}$} & \multicolumn{3}{|c|}{ Gübre dozları } & \multirow{2}{*}{\multicolumn{2}{|c|}{ Ortalama }} \\
\hline & & No & N5 & N10 & & \\
\hline \multirow{3}{*}{$\mathrm{K} 2$} & E1 & 20.04 & 12.91 & 13.87 & 15.61 & C \\
\hline & E2 & 16.76 & 23.31 & 15.80 & 18.63 & c \\
\hline & E3 & 38.34 & 37.19 & 35.45 & 36.99 & a \\
\hline \multicolumn{2}{|l|}{ Ortalama } & 25.05 & 24.47 & 21.71 & 23.74 & \\
\hline \multirow{3}{*}{ K4 } & E1 & 21.20 & 19.08 & 19.27 & 19.85 & C \\
\hline & E2 & 25.62 & 16.57 & 19.46 & 20.55 & c \\
\hline & E3 & 23.12 & 26.78 & 32.56 & 27.49 & $\mathrm{~b}$ \\
\hline \multicolumn{2}{|l|}{ Ortalama } & 23.31 & 20.81 & 23.76 & 22.63 & \\
\hline Karışım & E1 & 20.62 & 15.99 & 16.57 & 17.73 & $B$ \\
\hline lar & E2 & 21.19 & 19.94 & 17.63 & 19.59 & B \\
\hline Ort. & E3 & 30.73 & 31.98 & 34.01 & 32.24 & A \\
\hline Genel Ort & alama & 24.18 & 22.64 & 22.74 & 23.19 & \\
\hline \multicolumn{7}{|c|}{$\begin{array}{l}\text { Önemlilik: karışımlar ve gübre dozu önemsiz, ekim şekli önemli } \\
(P=0.000) \text {, karışım x ekim şekli etkileşimi önemli }(P=0.023) \text { ve } \\
\text { diğer etkileşimler önemsiz. }\end{array}$} \\
\hline
\end{tabular}

Çizelge 7. Korunganın ortalama $\mathrm{m}^{2}$ deki fide sayısı (adet $/ \mathrm{m}^{2}$ ).

\begin{tabular}{cccccc}
\hline \multirow{2}{*}{ Karışım } & Ekim & \multicolumn{3}{c}{ Gübre dozları } & \multirow{2}{*}{ Ortalama } \\
\cline { 3 - 5 } & şekli & N0 & N5 & N10 & \\
\hline \multirow{2}{*}{ K1 } & E1 & 45.37 & 38.66 & 36.81 & 40.28 \\
& E2 & 55.33 & 41.44 & 62.96 & 53.24 \\
& E3 & 30.09 & 32.41 & 29.86 & 30.79 \\
\hline Ortalama & & $43.60 \mathrm{ab}$ & $37.50 \mathrm{~b}$ & $43.21 \mathrm{ab}$ & 41.44 \\
\hline \multirow{2}{*}{ K2 } & E1 & 39.35 & 41.90 & 39.12 & 40.12 \\
& E2 & 45.83 & 62.97 & 51.39 & 53.39 \\
& E3 & 36.34 & 37.96 & 37.96 & 37.42 \\
\hline Ortalama & & $40.51 \mathrm{ab}$ & $47.61 \mathrm{a}$ & $42.82 \mathrm{ab}$ & 43.65 \\
\hline Karışım & $\mathrm{E} 1$ & 42.36 & 40.28 & 37.97 & $40.20 \mathrm{~B}$ \\
Ilar & $\mathrm{E} 2$ & 50.58 & 52.20 & 57.17 & $53.32 \mathrm{~A}$ \\
Ort. & $\mathrm{E} 3$ & 33.22 & 35.19 & 33.91 & $34.11 \mathrm{~B}$ \\
\hline Genel ortalama & 42.05 & 42.56 & 43.02 & 42.54
\end{tabular}

Önemlilik: karışımlar ve gübre dozu önemsiz, ekim şekli önemli $(P=0.000)$, karışım $x$ gübre dozu etkileşimi önemli $(P=0.033)$ ve diğer etkileşimler önemsiz.

Yapay mera karışımında bulunan korungada ekim şekli ve karışım x gübre dozu etkileşimi önemli, karışım, gübre dozu ve diğer etkileşimler önemsiz olmuştur (Çizelge 7). Korunganın $\mathrm{m}^{2}$ deki fide sayısı en yüksek 53.32 adet ile aynı sıraya ekimden elde edilirken, en az fide (34.11 ve 40.20 adet) farklı sıraya ve serpme ekilen parsellerde belirlenmiştir. Korunganın yer aldığı karışımlardaki fide sayıları azot dozlarına göre önemli ölçüde değişmiştir. Dekara $5 \mathrm{~kg} \mathrm{~N}$ uygulanan otlak ayrığı ve kılçıksız brom ile karışık ekilen korunganın $\mathrm{m}^{2}$ 'deki fide sayısı en yüksek (47.61 adet), aynı gübre dozunda otlak ayrığı ile ikili karışımında ise en az (37.50 adet) olmuştur. 
Yapılan uygulamaların ve etkileşimlerin çayır düğmesinin $\mathrm{m}^{2}$ 'deki fide sayısı üzerine önemli bir etkisi görülmemiştir. Tüm uygulamaların ortalaması olarak metrekeredeki fide sayısı 40.34 adet olarak saptanmıştır (Çizelge 8).

Çıkış oranı: Otlak ayrığı fidelerinin çıkış oranlarını ekim şekilleri ile karışım $x$ ekim şekl etkileşimi önemli seviyede etkilerken, karışımlar, gübre dozları ve diğer etkileşimler önemli bir etkiye sahip olmamıştır. Otlak ayrığında fide çıkış oranı farklı sıraya ekimde \%15.29 ile en yüksek seviyede yer alırken bunu \%11.42 ile aynı sıraya ekim ve \%10.04 ile serpme ekim takip etmiştir. Serpme ekim ve ayn sıraya ekim istatistiki olarak aynı grupta yer almıştır. Karışım $x$ ekim şekli etkileşiminde ise en fazla fide çıkış oranı korunga + otlak ayrığı + kılçıksız bromun oluşturduğu üçlü karışım ile farklı sıraya ekimden (\%18.08) elde edilirken, en az çıkış oranı (\%7.87) yine aynı karışım ile aynı sıraya yapılan ekimden elde edilmiştir (Çizelge 9).

Kılçıksız bromun fide çıkış oranı Çizelge 10'da verilmiştir. Çizelgeden de görüldüğü gibi ekim şekilleri fide çıkış oranına çok önemli seviyede etki etmiştir. Farklı sıraya ekimde çıkış oranı en yüksek olurken (\%31.69), serpme ekimde en düşük (\%17.42), ayn sıraya ekimde ise fide çıkışı \%19.25 olarak belirlenmiş. Karışım $x$ ekim şekli etkileşimi önemli bir etkiye sahip olmuştur. Kılçıksız bromda en yüksek fide çıkış oranı \%36.36 ile korunga, otlak ayrığı ve kılçıksız bromun bulunduğu karışım ile farklı sıraya yapılan uygulamadan elde edilmiştir. Bunu \%27.02 ile çayır düğmesi + otlak ayrığı + kılçıksız brom karışımı ile farklı sıraya yapılan ekimler izlemiştir.

Çizelge 8. Çayır düğmesinin ortalama $\mathrm{m}^{2}$ deki fide sayısı (adet $\left./ \mathrm{m}^{2}\right)$.

\begin{tabular}{|c|c|c|c|c|c|}
\hline \multirow[t]{2}{*}{ Karışım } & \multirow{2}{*}{$\begin{array}{l}\text { Ekim } \\
\text { şekli }\end{array}$} & \multicolumn{3}{|c|}{ Gübre Dozları } & \multirow{2}{*}{ Ortalama } \\
\hline & & No & N5 & N10 & \\
\hline \multirow{3}{*}{$\mathrm{K} 2$} & E1 & 40.22 & 45.73 & 28.65 & 38.20 \\
\hline & E2 & 49.86 & 43.80 & 45.18 & 46.28 \\
\hline & E3 & 25.07 & 21.21 & 44.90 & 30.39 \\
\hline Ortalama & & 38.38 & 36.91 & 39.58 & 38.29 \\
\hline \multirow{3}{*}{ K4 } & E1 & 35.81 & 31.95 & 33.06 & 33.61 \\
\hline & E2 & 59.78 & 51.24 & 39.39 & 50.14 \\
\hline & E3 & 40.22 & 43.53 & 46.56 & 43.43 \\
\hline Ortalama & & 45.27 & 42.24 & 39.67 & 42.39 \\
\hline \multirow{3}{*}{$\begin{array}{c}\text { Karışım } \\
\text { lar } \\
\text { Ort. }\end{array}$} & E1 & 38.02 & 38.84 & 30.85 & 35.90 \\
\hline & E2 & 54.82 & 47.52 & 42.29 & 48.21 \\
\hline & E3 & 32.64 & 32.37 & 45.73 & 36.91 \\
\hline \multicolumn{2}{|c|}{ Genel ortalama } & 41.83 & 39.58 & 39.62 & 40.34 \\
\hline
\end{tabular}

Çizelge 9. Otlak ayrığı fidelerinin çıkış oranları (\%).

\begin{tabular}{cccccl}
\hline \multirow{2}{*}{ Karışım } & Ekim & \multicolumn{3}{c}{ Gübre dozları } & \multirow{2}{*}{ Ortalama } \\
\cline { 3 - 5 } & şekli & N0 & N5 & N10 & \\
\hline \multirow{2}{*}{ K1 } & E1 & 8.64 & 15.39 & 8.64 & $10.89 \mathrm{CDEF}$ \\
& E2 & 15.86 & 12.01 & 11.74 & $13.20 \mathrm{BC}$ \\
& E3 & 17.48 & 16.12 & 18.29 & $17.30 \mathrm{AB}$ \\
\hline Ortalama & & 13.99 & 14.51 & 12.89 & 13.79 \\
\hline \multirow{2}{*}{ K2 } & E1 & 8.64 & 7.56 & 7.83 & $8.01 \mathrm{EF}$ \\
& E2 & 8.50 & 9.58 & 5.53 & $7.87 \mathrm{~F}$ \\
& E3 & 16.73 & 18.49 & 19.03 & $18.08 \mathrm{~A}$ \\
\hline Ortalama & & 11.29 & 11.88 & 10.80 & 11.32 \\
\hline \multirow{2}{*}{ K3 } & E1 & 11.88 & 15.11 & 10.59 & $12.53 \mathrm{CD}$ \\
& E2 & 13.90 & 12.68 & 16.73 & $14.44 \mathrm{ABC}$ \\
& E3 & 13.02 & 12.01 & 11.94 & $12.33 \mathrm{CDE}$ \\
\hline Ortalama & & 12.93 & 13.27 & 13.09 & 13.10 \\
\hline \multirow{2}{*}{ K4 } & E1 & 9.58 & 7.96 & 8.64 & $8.73 \mathrm{DEF}$ \\
& E2 & 8.64 & 13.36 & 8.50 & $10.16 \mathrm{CDEF}$ \\
\hline Ortalama & E3 & 13.90 & 14.84 & 11.61 & $13.45 \mathrm{BC}$ \\
\hline Karışım & E1 & 9.68 & 11.50 & 8.92 & $10.04 \mathrm{~B}$ \\
lar & E2 & 11.72 & 11.91 & 10.63 & $11.42 \mathrm{~B}$ \\
Ort. & E3 & 15.28 & 15.37 & 15.22 & $15.29 \mathrm{~A}$ \\
\hline Genel ortalama & 12.23 & 12.93 & 11.59 & 12.25 \\
\hline
\end{tabular}

Önemlilik: karışımlar ve gübre dozu önemsiz, ekim şekli önemli $(P=0.000)$, karışım $x$ ekim şekli etkileşimi önemli $(P=0.004)$ ve diğer etkileşimler önemsiz.

Çizelge 10. Kılçıksız brom fidelerinin çıkış oranları (\%).

\begin{tabular}{cccccc}
\hline \multirow{2}{*}{ Karışım } & Ekim & \multicolumn{3}{c}{ Gübre dozları } & \multirow{2}{*}{ Ortalama } \\
\cline { 3 - 5 } & şekli & N0 & N5 & N10 & \\
\hline \multirow{2}{*}{ K2 } & E1 & 19.70 & 12.69 & 13.63 & $15.34 \mathrm{c}$ \\
& E2 & 16.48 & 22.91 & 15.53 & $18.31 \mathrm{c}$ \\
& E3 & 37.69 & 36.55 & 34.85 & $36.36 \mathrm{a}$ \\
\hline Ortalama & & 24.62 & 24.05 & 21.34 & 23.34 \\
\hline \multirow{2}{*}{ K4 } & E1 & 20.83 & 18.75 & 18.94 & $19.51 \mathrm{c}$ \\
& E2 & 25.19 & 16.29 & 19.13 & $20.20 \mathrm{c}$ \\
& E3 & 22.73 & 26.33 & 32.01 & $27.02 \mathrm{~b}$ \\
\hline Ortalama & & 22.92 & 20.45 & 23.36 & 22.24 \\
\hline Karışım & E1 & 20.26 & 15.72 & 16.29 & $17.42 \mathrm{~B}$ \\
lar & E2 & 20.83 & 19.60 & 17.33 & $19.25 \mathrm{~B}$ \\
Ort. & E3 & 30.21 & 31.44 & 33.43 & $31.69 \mathrm{~A}$ \\
\hline \multicolumn{2}{c}{ Genel ortalama } & 23.77 & 22.25 & 22.35 & 22.79 \\
\hline \multicolumn{2}{l}{ Onamn }
\end{tabular}

Önemlilik: karışımlar ve gübre dozu önemsiz, ekim şekli önemli $(P=0.000)$, karışım $x$ ekim şekli etkileşimi önemli $(P=0.024)$ ve diğer etkileşimler önemsiz.

Korunganın fide çıkış oranını ekim şekli, karışım $x$ gübre dozu ile bütün uygulamaların etkileşimleri önemli seviyede etkilemiştir. En yüksek fide çıkış oranı $\% 53.32$ ile aynı sıraya ekimde belirlenirken, bunu $\% 40.20$ ile serpme ekim, \%34.10 ile farklı sıraya ekim takip etmiştir. Fakat serpme ekim ile farklı sıraya ekim arasındaki değişim istatistiki olarak önemsiz olmuştur (Çizelge 11). 
Çizelge 11. Korunga fidelerinin çıkış oranı (\%).

\begin{tabular}{|c|c|c|c|c|c|}
\hline \multirow{2}{*}{ Karışım } & \multirow{2}{*}{$\begin{array}{l}\text { Ekim } \\
\text { şekli }\end{array}$} & \multicolumn{3}{|c|}{ Gübre dozları } & \multirow{2}{*}{$\begin{array}{c}\text { Ortalam } \\
\quad \mathrm{a}\end{array}$} \\
\hline & & N0 & N5 & N10 & \\
\hline \multirow[t]{3}{*}{ K2 } & $\overline{E 1}$ & $\begin{array}{l}45.37 b c \\
d e\end{array}$ & $38.66 \mathrm{cde}$ & $36.81 \mathrm{cde}$ & 40.28 \\
\hline & E2 & $\begin{array}{l}55.33 a \\
b\end{array}$ & $\begin{array}{l}41.44 b c d \\
\text { e }\end{array}$ & $62.96 a$ & 53.24 \\
\hline & E3 & $30.09 \mathrm{e}$ & $32.41 \mathrm{de}$ & $29.86 \mathrm{e}$ & 30.79 \\
\hline Ortalama & & $\begin{array}{c}43.60 \\
\text { ab }\end{array}$ & $37.50 \mathrm{~b}$ & $43.21 \mathrm{ab}$ & 41.44 \\
\hline \multirow[t]{3}{*}{ K4 } & E1 & $\begin{array}{l}39.35 c d \\
e\end{array}$ & $\begin{array}{c}41.90 \mathrm{bcd} \\
\mathrm{e}\end{array}$ & 39.12cde & 40.12 \\
\hline & E2 & $\begin{array}{l}45.83 b c \\
d\end{array}$ & $62.97 a$ & $51.39 a b c$ & 53.39 \\
\hline & E3 & $\begin{array}{l}36.34 d \\
e^{-3}\end{array}$ & $37.96 \mathrm{cde}$ & $37.95 \mathrm{cde}$ & 37.42 \\
\hline Ortalama & & $\begin{array}{c}40.51 \\
a b\end{array}$ & $47.61 \mathrm{a}$ & $42.82 \mathrm{ab}$ & 43.65 \\
\hline \multirow{3}{*}{$\begin{array}{c}\text { Karışım } \\
\text { lar } \\
\text { Ort. }\end{array}$} & E1 & 42.36 & 40.28 & 37.96 & $40.20 \mathrm{~B}$ \\
\hline & E2 & 50.58 & 52.20 & 57.17 & $53.32 \mathrm{~A}$ \\
\hline & E3 & 33.22 & 35.18 & 33.91 & $34.10 \mathrm{~B}$ \\
\hline \multicolumn{2}{|c|}{ Genel ortalama } & 42.05 & 42.56 & 43.01 & 42.54 \\
\hline
\end{tabular}

Önemlilik: karışımlar ve gübre dozu önemsiz, ekim şek $(P=0.000)$, karışım $x$ gübre dozu etkileşimi $(P=0.032)$ ve karışı $x$ ekim şekli $x$ gübre dozu $(P=0.035)$ önemli diğer etkileşimler önemsiz.

Korunga fidelerinde en yüksek çıkış oranı (\%62.96) dekara $10 \mathrm{kgN}$ uygulayarak aynı sıraya ekilen otlak ayrığı ile karışımından elde edilirken, en düşük fide çıkış oranı (\%29.86) aynı karışımın farklı sıraya ekim ve aynı gübre dozundan elde edilmiştir.

Çayır düğmesinin fide çıkış oranını ekim şekli ile karışım $x$ ekim şekli etkileşimi önemli seviyede etkilemiştir. Diğer uygulamalar ve etkileşimler istatistiki olarak önemli bir etki etmemiştir. Fide çıkış oranı ayn sıraya ekimde \%48.21 ile en yüksek olurken \%32.47 ile en az olmuştur. Karışım x ekim şekli etkileşimde çayır düğmesi + otlak ayrığı + kılçıksız brom karışımı ile aynı sıraya ekimden en yüksek fide çıkış oranı elde edilirken (\%50.14), çayır düğmesi + otlak ayrığı ile farklı sıraya ekimden en düşük fide çıkışı (\%21.50) belirlenmiştir (Çizelge 12).

Karışımda bulunan otlak ayrığı, kılçıksız brom,

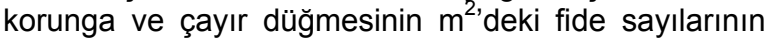
serpme ekimde düşük çıkması, bu ekim şeklinde ekim derinliğini ayarlamak mümkün olmadığından tohumlar farklı derinliklere düşmesinden kaynaklanmıştır. Ayn zamanda bu durum çıkışta düzensiz bir dağılım meydana getirmiştir. Benzer sonuç Tekeli (1977)'nin yürüttüğü araştırmada da ortaya konmuştur. Otlak ayrığı ve kılçıksız bromun farklı sıraya ekimlerinde $\mathrm{m}^{2}$ 'deki fide sayısı en yüksek olmuştur. Aynı sıraya
Çizelge 12. Çayır düğmesi fidelerinin çıkış oranlaıı (\%).

\begin{tabular}{cccccl}
\hline \multirow{2}{*}{ Karışım } & Ekim & \multicolumn{3}{c}{ Gübre dozları } & \multirow{2}{*}{ Ortalama } \\
\cline { 3 - 5 } & şekli & N0 & N5 & N10 & \\
\hline \multirow{2}{*}{ K2 } & E1 & 40.22 & 45.70 & 28.65 & $38.19 \mathrm{ab}$ \\
& E2 & 49.86 & 43.80 & 45.18 & $46.28 \mathrm{ab}$ \\
& E3 & 25.07 & 21.21 & 18.24 & $21.50 \mathrm{c}$ \\
\hline Ortalama & & $\mathbf{3 8 . 3 8}$ & $\mathbf{3 6 . 9 0}$ & $\mathbf{3 0 . 6 9}$ & $\mathbf{3 5 . 3 3}$ \\
\hline \multirow{2}{*}{ K4 } & E1 & 35.81 & 31.95 & 33.06 & $33.61 \mathrm{bc}$ \\
& E2 & 59.78 & 51.24 & 39.39 & $50.14 \mathrm{a}$ \\
& E3 & 40.22 & 43.53 & 46.56 & $43.43 \mathrm{ab}$ \\
\hline Ortalama & & $\mathbf{4 5 . 2 7}$ & $\mathbf{4 2 . 2 4}$ & $\mathbf{3 9 . 6 7}$ & $\mathbf{4 2 . 3 9}$ \\
\hline Karışım & E1 & 38.01 & 38.83 & 30.85 & $\mathbf{3 5 . 9 0 A B}$ \\
lar & E2 & 54.82 & 47.52 & 42.29 & $\mathbf{4 8 . 2 1 A}$ \\
Ort. & E3 & 32.64 & 32.37 & 32.40 & $\mathbf{3 2 . 4 7 B}$ \\
\hline \multicolumn{2}{c}{ Genel ortalama } & $\mathbf{4 1 . 8 3}$ & $\mathbf{3 9 . 5 7}$ & $\mathbf{3 5 . 1 8}$ & $\mathbf{3 8 . 8 6}$ \\
\hline
\end{tabular}

Önemlilik: karışımlar ve gübre dozu önemsiz, ekim şekli önemli $(P=0.007)$, karışım $x$ ekim şekli etkileşimi önemli $(P=0.022)$ ve diğer etkileşimler önemsiz.

yapılan ekimde ekim derinliği bütün bitkilerde aynı olduğu için iri tohumlu olan korunga ve çayır düğmesinin çıkışı küçük tohumlu olan otlak ayrığı ve kılçıksız broma göre daha iyi olmuştur. Bu rekabet üstünlüğü çayır düğmesi ve korunganın fide sayısını artırmasına, daha zayıf gelişen otlak ayrığı ve kılçıksız bromun fide sayısının azalmasına yol açmıştır.

\section{Sonuç}

Araştırmada karışımlar, ekim şekilleri ve azot dozu uygulamaları karışımda bulunan otlak ayrığı, kılçıksız brom, korunga ve çayır düğmesinin fide kuru ağırlığına önemli bir etkide bulunmamıştır. Metrekaredeki fide sayısı ve fide çıkış oranı ekim şekilleri ile etkilenmiştir. Küçük tohumlu olan otlak ayrığı ve kılçıksız bromun hem metrekaredeki fide sayısı hem de fide çıkış oranı farklı sıraya yapılan ekimde en fazla olmuştur. Korungada ise metrekaredeki fide sayısı ve fide çıkış oranı aynı sıraya yapılan ekimde en yüksek olmuştur. Çayır düğmesinde metrekaredeki fide sayısına hiçbir uygulama etki etmemiştir. Fakat fide çıkış oranı aynı sıraya ekimde en yüksek değerde yer almıştır.

\section{Kaynaklar}

Albayrak, S. 2003. Ankara ekolojik koşullarında yapay mera kurulması üzerine bir arştırma. Ankara Üniv. Fen Bil. Enst. Tarla Bitkileri Ana Bilim Dalı, Doktora Tezi, 166s.

Bakır, Ö., A. Eraç ve S. Altınok. 1992. Farklı ekim yöntemlerinde adi otlak ayrığı (Agropyron cristatum $(\mathrm{L})$ Gaertn.) ve salyangoz yoncası (Medicago scutellata Mill.) ile suni mera kurma olanakları üzerinde araştırmalar. Ankara Üniv. Ziraat Fak. Yıllığı. 41®12'den ayrı basım),95-105. 

gelişmesine etkileri"

Düzgüneş, O., T. Kesici, O. Kavuncu ve F. Gürbüz. 1987. Araştırma ve Deneme Metotları (İstatistik Metotları II). Ankara Üniv. Ziraat Fak. Yay.:1021, Ders Kitabı:295, $381 \mathrm{~s}$.

Karakurt, E. 2000. Bazı Buğdaygil Yem Bitkilerinde Azotlu Gübre Dozlarının Önemli Tarımsal karakterler Üzerine Etkileri. Ankara Üniv. Fen Bilimleri Enst. Tarla Bitkileri Anabilim Dalı, Doktora Tezi, Ankara,125 s.

Kurt, Ö. 1978. Orta Anadolu kıraç koşullarında bir yapay mera karışımının tohum oranları üzerinde araştırmalar. Ankara Üniv. Ziraat Fak. Tarla Bitkileri Bölümü, Ankara, Doktora Tezi, $86 \mathrm{~s}$.

Lafond, G. P. and B. D. Fowler. 1989. Soil temperature and water content, seeding depth, and simulated rainfall effects on winter wheat emergence. Argon. J. 81:609614.

Mutz, J. L. and C. J. Scifres. 1975. Soil texture and planting depth influence buffalograss emergence. J.Range Manage. 28:222-224.

Sepaskhah, A. R. and E. Raessi Ardekani. 1978. Effect of soil matric potential and seeding depth on emergence of barley. Argon. J. 70:728-731.
Tekeli, A. E. 1977. Orta Anadolu koşullarında suni mera tohum karışımlarının ekim metotları üzerinde araştırmalar. Ankara Üniv. Ziraat Fak. Yem Bitkileri Çayır Mera Kürsüsü, Doktora Tezi.78s.

Young, J. A. 1992. Population-level processes: Seed and seedbed ecology. P.37-46. In: J.C.Chambers and G.W. Wade (ed.) Evaluating reclamation success: The ecological considerations. Proc.Symp. (Amer.Soc.for Surface Mining and Reclamation, Charleston, Wv24-26 Apr.1990). USDA Forest Serv. Gen. Tech.Rep.NE164.USDA-FS, Radnor, Penn.

Vallentine, J. F. 1980. Range Development and Improvements, 2nd ed. Brigham Young Univ.Press, Provo, Utah.

\section{İletişim adresi:}

Altıngül ÖZASLAN PARLAK

Çanakkale Onsekiz Mart Üniv.

Ziraat Fak. Tarla Bitkileri Bölümü- Çanakkale

Tel: 0286 2180018/1354

E-posta: gulozaslan@yahoo.com 